\title{
Life course epidemiology: recognising the importance of adolescence
}

\author{
Russell M Viner, ${ }^{1}$ David Ross, ${ }^{2}$ Rebecca Hardy, ${ }^{3}$ Diana Kuh, ${ }^{3}$ \\ Christine Power, ${ }^{1}$ Anne Johnson, ${ }^{4}$ Kaye Wellings, ${ }^{2}$ Jim McCambridge, ${ }^{2}$ \\ Tim J Cole, ${ }^{1}$ Yvonne Kelly, ${ }^{4}$ G David Batty ${ }^{4}$
}

Life course epidemiology may be conceptualised as "the study of long term effects on later health or disease risk of physical or social exposures during gestation, childhood, adolescence, young adulthood and later adult life." ${ }^{\prime}$ Adolescence, the period between childhood and adulthood defined by the WHO as 10-19 years, has an uneasy status in epidemiology. On the one hand, adolescents, who now number over 1.2 billion worldwide-around 20\% of the global population-are highly visible in population-based studies. Young people's behaviours have been an important subject of epidemiological inquiry, from tobacco and alcohol use to violence and sexual activity. Yet, concepts of adolescence as a discrete stage in the life course have been much less discussed within epidemiology. This is particularly so in studies of the developmental origins of adult health and disease, which have focused on the influence on adult health outcomes of exposures from the period of rapid physiological change in very early life. Similarly, investigators in the field of the social determinants of health and disease have concentrated their efforts on the effects of parenting and education in early childhood.

With the aim of developing our understanding of the place of adolescence in a life course framework, in May 2013, we organised a joint workshop between UCL and the London School of Hygiene and Tropical Medicine.

\section{AFTER INFANCY, ADOLESCENCE IS THE PERIOD OF GREATEST AND MOST RAPID DEVELOPMENT}

Studies of the biological embedding of early life experiences have focused largely on prenatal or infant life, and have led to

${ }^{1}$ UCL Institute of Child Health, London, UK; ${ }^{2}$ London School of Hygiene \& Tropical Medicine, London, UK;

${ }^{3}$ MRC Unit for Lifelong Health and Ageing at University College London, London, UK; ${ }^{4}$ Department of Epidemiology \& Public Health, University College London, London, UK

Correspondence to Professor Russell M Viner, UCL Institute of Child Health, 30 Guilford St. London WC1N 1EH, UK; r.viner@ucl.ac.uk the understanding that periods of rapid organ system development during these phases of life are critical to adult health. ${ }^{1}$ Yet, adolescence is second only to fetal and infant life in the rapidity of growth and pervasiveness of change across body systems.

Puberty is one of the central dramas of the human life course, and results in very rapid somatic growth, brain development, sexual maturation and attainment of reproductive capacity. It is accompanied by final maturation of multiple organ systems, major central nervous system changes and dramatic psychosocial change. ${ }^{2}$ Human puberty is unique in the animal world. We are the only animals to have major brain development and a somatic growth spurt at the same time as puberty, and the only animals aside from chimpanzees and gorillas in which the earliest phase of puberty (adrenarche) is identifiable. $^{2}$ The discovery of continued brain development through adolescence has been one of the great advances of neuroscience in the past 20 years. Brain imaging techniques have revealed that there is a dramatic spurt in brain development during adolescence that continues until the mid-20s, with marked development of both cortical and subcortical structures in a manner linked with age and puberty. ${ }^{3}$

In parallel with such biological developments during adolescence, there are marked psychosocial developmental changes, including in the pervasive social role and associated behavioural change. Social transitions from dependent child towards stronger peer affiliation and development of intimate partner relationships, and from primary through secondary to further education and employment are accompanied by new behaviours acquired across personal, social and health domains. These include initiation of many important health-related behaviours, such as smoking, alcohol and drug use, physical activity and sexual behaviours, and patterns initiated in adolescence track strongly into adult life. Of the five leading risk factors for global disability adjusted life years (DALYs) lost identified in the
2010 Global Burden of Disease study, tobacco (the second ranked for global DALYs) and alcohol use (third ranked) are largely initiated in adolescence. ${ }^{4}$ Since the 1960 s, approximately $80 \%$ of smoking initiation has been consistently found to taken place in adolescence in high-income countries, and many resource-poor countries now share this pattern of initiation. A further 4 of the top 10 global risk factors in the 2010 Global Burden of Disease study are strongly determined in adolescence, that is, low fruit consumption (ranked 4), high body mass index (BMI; ranked 6), high fasting plasma glucose (ranked 7), and physical inactivity and low physical activity (ranked 10). ${ }^{4}$

\section{EVIDENCE THAT ADOLESCENCE MAY BE A CRITICAL PERIOD FOR LATER HEALTH AND DISEASE}

The rapid development during adolescence points to the possibility that the adolescent period may be a critical or sensitive period for later health and disease. Some of the strongest evidence for this comes from studies of the timing of puberty. This is most apparent in evidence accumulated across the British birth cohort studies.

In studies from the MRC National Survey of Health and Development (the 1946 British Birth Cohort), it has been demonstrated that pubertal timing influenced BMI and blood pressure in midlife in men. ${ }^{5}$ Similarly, in the 1958 National Child Development Study, pubertal timing was associated with BMI change from childhood to adulthood. ${ }^{6}$ In a recent systematic review of these and other studies, there was substantial longitudinal evidence that early puberty increased risk of cardiovascular disease and a range of negative cardiometabolic outcomes in addition to obesity. ${ }^{7}$ This risk may operate in part through programming of metabolic factors such as insulin-like growth factor $1^{8}$ as well as directly through obesity. ${ }^{7}$ There is evidence that pubertal timing or related pubertal weight gain may influence the prevalence and presentation of a wide range of other adverse outcomes, from common health problems such as asthma, epilepsy, chronic kidney disease, thyroid dysfunction, lean to fat mass ratios and diabetes prevalence to pain perception and mental health problems such as depression, eating disorders and schizophrenia. $^{2}$

Other evidence that adolescence may be a critical period in human development comes from observations that $75 \%$ of lifetime mental health disorders have their onset before age 25 years, with the peak 
age of onset for many being during adolescence. ${ }^{9}$ This is likely to be related to dramatic brain development during the second decade of life. Further, the timing of puberty is increasingly recognised to influence development of grey matter, white matter and subcortical structures, although further work is needed to understand the interaction of puberty and brain development, and its implications for health and behaviour across the life course. $^{3}$

The research and policy interest in behaviours relevant to health makes adolescence a critical period for behavioural risk, particularly given increasing evidence that these behaviours, once initiated, track into adult life. While tracking-maintenance of behaviours across the life course -is strong for smoking and alcohol use, socioeconomic status and personal assets such as cognitive abilities can modify their stability. ${ }^{10}$ Alcohol provides an excellent example of a behaviour where there is clear evidence that adolescent initiation is important for adult alcohol burden, yet the nature of the pathways between adolescent and adult drinking is not well understood. $^{11}$

\section{CONCLUSIONS AND FUTURE DIRECTIONS}

Brain plasticity, rapid pubertal maturation of all organ systems, and dynamic behavioural and social change make adolescence a time of great importance for later health -and therefore also a time of great potential for intervention. While recognising the importance of continuity across the life course, adolescence should be regarded as a key period within the life course, distinct from childhood or adulthood, and the second sensitive meeting held between University College London and

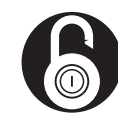

\section{OPEN ACCESS}

developmental period in the life course after the fetal period and infancy.

Twitter Follow Russell Viner at @russellviner

Correction notice This article has been corrected since it was published Online First. The provenance and peer review statement has been corrected.

Acknowledgements This article arose from a the London School of Hygiene and Tropical Medicine on 15 May 2013. The authors would like to thank other speakers and participants in that meeting for a stimulating discussion and for encouragement to pursue further work on the place of adolescence in life course epidemiology.

Contributors The idea for the article was developed by all authors. RMV and GDB led the writing of the paper. All authors contributed to editing the article and to the final submitted version.

Competing interests None.

Provenance and peer review Commissioned; internally peer reviewed.

Received 26 November 2014

Accepted 21 December 2014

Published Online First 2 February 2015

http://dx.doi.org/10.1136/jech-2015-205607

J Epidemiol Community Health 2015;69:719-720. doi:10.1136/jech-2014-205300

\section{REFERENCES}

1 Kuh D, Ben-Shlomo Y, Lynch J, et al. Life course epidemiology. J Epidemiol Community Health 2003:57:778-83.

2 Patton GC, Viner R. Pubertal transitions in health. Lancet 2007:369:1130-9.

3 Goddings A-L, Burnett Heyes S, Bird G, et al. The relationship between puberty and social emotion processing. Dev Sci 2012;15:801-11. regional mortality from 235 causes of death for 20 age groups in 1990 and 2010: a systematic analysis for the Global Burden of Disease Study 2010. Lancet 2012;380:2095-128.

5 Hardy R, Kuh D, Whincup PH, et al. Age at puberty and adult blood pressure and body size in a British birth cohort study. I Hypertens 2006;24:59-66.

6 Power C, Lake JK, Cole TJ. Body mass index and height from childhood to adulthood in the 1958 British born cohort. Am J Clin Nutr 1997;66:1094-101.

7 Prentice $P$, Viner RM. Pubertal timing and adult obesity and cardiometabolic risk in women and men: a systematic review and meta-analysis. Int $J$ Obes (Lond) 2013;37:1036-43.

Open Access This is an Open Access article distributed in accordance with the Creative Commons Attribution Non Commercial (CC BY-NC 4.0) license, which permits others to distribute, remix, adapt, build upon this work non-commercially, and license their derivative works on different terms, provided the original work is properly cited and the use is noncommercial. See: http://creativecommons.org/licenses/ by-nc/4.0/

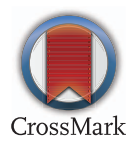

To cite Viner RM, Ross D, Hardy R, et al. J Epidemiol Community Health 2015;69:719-720. determines serum insulin-like grenth factor- in late adulthood. J Clin Endocrinol Metab 2006;91:3150-7.

9 Kessler RC, Berglund P, Demler O, et al. Lifetime prevalence and age-of-onset distributions of DSM-IV disorders in the National Comorbidity Survey Replication. Arch Gen Psychiatry 2005;62:593-602.

10 Jefferis BJ, Manor O, Power C. Cognitive development in childhood and drinking behaviour over two decades in adulthood. J Epidemiol Community Health 2008;62:506-12.

11 Maimaris W, McCambridge J. Age of first drinking and adult alcohol problems: systematic review of prospective cohort studies. J Epidemiol Community Health 2014;68:268-74.

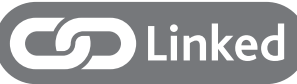

4 Lozano R, Naghavi M, Foreman K, et al. Global and 